\title{
陕西省森林土壤固碳特征及其影响因素
}

\author{
李 茜 1,2 王芳 ${ }^{3}$ 曹 扬 4,5 彭守璋 4,5 陈云明 $4,5^{*}$
}

${ }^{1}$ 中国科学院教育部水土保持与生态环境研究中心, 陕西杨凌 712100; ${ }^{2}$ 中国科学院大学, 北京 100049 ; ${ }^{3}$ 延安市宝塔区水务局水土保持监督管理站, 陕西延安 716009 ; ${ }^{4}$ 西北农林科技大学黄土高原土壤侵蚀与早地农业国家重点实验室, 陕西杨凌 $712100 ;{ }^{5}$ 中国科学院水利部水土保持研究所, 陕西杨 凌 712100

摘 要 森林土壤碳库在全球碳循环中发挥着重要的作用。为明确陕西省森林土壤固碳特征及其影响因素, 基于2009年森林 清查资料和2011年样地实测数据, 分析了陕西省森林土壤碳储量、碳密度及其分布特征和影响因素。结果表明: 陕西省森林 土壤碳储量为 $579.68 \mathrm{Tg}$, 以软阔与硬阔类林土壤碳储量占比最大, 占全省森林土壤碳储量的 $36.35 \%$ 。天然林的碳储量为 $467.17 \mathrm{Tg}$, 是人工林的 4.15 倍。各龄组中, 幼龄林和中龄林是陕西省森林土壤总碳储量的主要贡献者, 约占总碳储量的 $57.30 \%$ 。陕西省森林土壤平均碳密度为 $90.68 \mathrm{t} \cdot \mathrm{hm}^{-2}$, 以桦木林最高, 为 $141.74 \mathrm{t} \cdot \mathrm{hm}^{-2}$ 。不同龄组森林的土壤碳密度以中龄林最 高; 同一龄组中, 天然林的土壤碳密度高于人工林, 说明天然林的碳固存能力高于人工林。陕西省森林土壤碳储量和碳密度 的地理空间分布格局不尽相同, 体现了森林覆盖面积对土壤碳储量的影响, 其中, 榆林市的森林土壤碳储量和碳密度均处于 陕西省最低水平, 在此地可适当加强人工造林, 科学管理森林能显著提升区域的碳汇能力。陕西省森林土壤碳密度随经纬度 和年平均气温的增加逐渐降低, 随海拔高度与年降水量的增加逐渐升高。该研究为我国省域尺度上森林土壤碳库的精确估算 提供了一定的数据基础。

关键词＼cjkstart森林土壤；碳储量；碳密度；空间分布；影响因素

引用格式: 李茜, 王芳, 曹扬, 彭守璋, 陈云明 (2017). 陕西省森林土壤固碳特征及其影响因素. 植物生态学报, 41, 953-963. doi: 10.17521/cjpe.2017.0102

\section{Soil carbon storage and its determinants in the forests of Shaanxi Province, China}

\author{
LI Xi ${ }^{1,2}$, WANG Fang ${ }^{3}$, CAO Yang ${ }^{4,5}$, PENG Shou-Zhang ${ }^{4,5}$, and CHEN Yun-Ming, ${ }^{4 *}$ \\ ${ }^{1}$ Research Center of Institute of Soil and Water Conservation and Ecological Environment, Chinese Academy of Sciences and Ministry of Education, Yangling, \\ Shaanxi 712100, China; ${ }^{2}$ University of Chinese Academy of Sciences, Beijing 100049, China; ${ }^{3}$ Water and Soil Conservation Supervision and Management \\ Station of Baota District, Yanan, Shaanxi 716009; ${ }^{4}$ State Key Laboratory of Soil Erosion and Dryland Farming on Loess Plateau, Northwest A\&F University, \\ Yangling, Shaanxi 712100, China; ${ }^{5}$ Institute of Soil and Water Conservation, Chinese Academy of Sciences and Ministry of Water Resources, Yangling, Shaan- \\ xi 712100, China
}

\begin{abstract}
Aims The bank of soil carbon of forests plays an important role in the global carbon cycle. Our aim is to understand the characteristics of soil carbon storage and its determinants in the forests in Shaanxi Province.

Methods The data of forest inventory in 2009 and resampling in 2011 were used to analyze the characteristics of soil carbon storage and its determinants in the forest soil in Shaanxi Province.

Important findings The soil carbon storage in the forests in Shaanxi Province was 579.68 Tg. Soil carbon storage of Softwood and Hardwood forests were the highest among all forest types, accounting for 36.35\% of the whole province forest soil carbon storage. The forest soil carbon storage was 4.15 times greater in the natural forest (467.17 Tg) than that in the plantations. The young and middle-aged forests were the main contributors to the total carbon storage across all age groups, accounting for about $57.30 \%$ of the total forest soil carbon storage. The average soil carbon density of forests in Shaanxi Province was $90.68 \mathrm{t} \cdot \mathrm{hm}^{-2}$, in which the soil carbon density of Betula forests was the highest $\left(141.74 \mathrm{t} \cdot \mathrm{hm}^{-2}\right)$. Soil carbon density of different forest types were gradually decreased with soil depth. In addition, it was highest in middle-aged forest. Soil carbon density was higher in the natural forest ecosystems than that in the plantations within the each age group, indicating natural forest ecosystems have higher capacity of carbon sequestration. Differences in the spatial patterns between carbon storage and density indicated that carbon storage was related to forest coverage. The soil carbon density and storage of forests in Yulin were the lowest across the province. This suggests that, in order to enhance the regional carbon sequestration capacity in this region, we need to appropriately strengthen artificial afforestation activities and manage them
\end{abstract}

收稿日期Received: 2017-04-14 接受日期Accepted: 2017-07-09

* 通信作者Author for correspondence (E-mail: ymchen@ms.iswc.ac.cn) 
scientifically and rationally. The soil carbon density of forests in Shaanxi Province decreased with the increase of longitude, latitude, and annual temperature, but increased with the increase of altitude and annual rainfall. This study provides data basis for provincial estimation of forest soil carbon bank in China.

Key words forest soils; carbon storage; carbon density; spatial distribution; influencing factors

Citation: Li X, Wang F, Cao Y, Peng SZ, Chen YM (2017). Soil carbon storage and its determinants in the forests of Shaanxi Province, China. Chinese Journal of Plant Ecology, 41, 953-963. doi: 10.17521/cjpe.2017.0102

土壤碳库是陆地生态系统中最大的碳库, 控制 着地球表层各系统之间的碳循环。据估计, 全世界 土壤有机碳储量约为1 $550 \mathrm{Pg}(\mathrm{Lal}, 2004)$, 是植被 碳库的 2 至 3 倍, 是大气碳库的 2 倍 (Smith et al., 2008)。由于土壤的呼吸作用, 土壤碳库较小幅度的 变化就可能影响生态系统各组分的碳交换过程, 对 陆地生态系统碳循环产生至关重要的影响。森林作 为陆地生态系统的主体, 是陆地上最大的碳储库和 碳汇，其土壤碳拒量约占陆地土壤的73\% (Post et al., 1982), 因此森林土壤碳库在调节全球碳平衡与 缓减温室气体浓度中具有举足轻重的作用。

目前, 已有不少学者对中国森林土壤碳库进行 了研究, 如周玉荣等(2000)、李克让等(2003)和李江 (2008)在全国尺度上的研究, 以及黄从德等(2008)、 王新闯等(2011)和汲玉河等(2016)在省域尺度上的 研究, 均表明土壤碳库具有很高的变异性。黄从德 等(2008)和王新间等(2011)的研究表明, 土壤有机 碳储量随经度、纬度和海拔高度呈一定的分布, 但 这种分布可能因研究区域的不同而有所差异(黄从 德等, 2008; 王新闯等, 2011), 因此, 有必要对森林 土壤碳储量随环境因子的变化规律进行进一步探 究。此外, 已有研究多基于土壤普查资料和文献数 据, 估算结果可能存在一定的不确定性, 因此, 有 必要结合实测数据对省域尺度上的森林土壤碳库及 其影响因子进行研究。

陕西省生态环境脆弱、水土流失严重, 是我国 退化生态恢复与重建的重点地区。近年来, 陕西省 开展了天然林资源保护和退耕还林等一批重点生态 建设工程, 使该省植被覆盖状况得到了很大的改善 (曹扬等, 2014), 森林覆盖率达 $41.4 \%$, 并成为西北 地区森林资源最丰富的省份(康永祥等, 2010; 马长 欣等, 2010), 在固碳、增汇及减排方面都发挥着重 要作用。目前, 对陕西省森林土壤固碳特征的研究 大多基于不同植被类型和不同区域(崔静等, 2012; 王琼芳等, 2013; 宋超等, 2015), 崔高阳等(2015)和 刘冰燕(2015)在研究陕西省森林生态系统碳库时对
森林土壤碳库进行了探讨, 但并未涉及其分布特征 与影响因素。因此, 本研究基于清查资料与样地实 测数据, 对陕西省森林土壤碳储量、碳密度及其分 布特征与主要影响因素进行了分析, 以期进一步了 解陕西省森林土壤固碳现状, 为我国区域尺度森林 土壤碳库的更精确估算提供数据基础。

\section{1 材料和方法}

\section{1 研究区域概况}

陕西省 $\left(105.29^{\circ}-111.15^{\circ} \mathrm{E}, 31.42^{\circ}-39.35^{\circ} \mathrm{N}\right)$ 地 处中国西北地区东部, 南北长约870 km, 东西宽达 $500 \mathrm{~km}$, 土地总面积为 20.58 万 $\mathrm{km}^{2}$ 。全省地形复杂, 地势由南北向中间呈下降趋势, 分别为秦巴山地 (海拔200-3 000 m)、关中平原(海拔320-800 m) 和陕 北黄土高原(海拔800-1 700 m)。整体上属于大陆性 季风气候, 气候类型依次为北亚热带气候、暖温带 气候和温带气候, 南北差异较大。全省平均年降水 量为 $576.9 \mathrm{~mm}$, 年平均气温为 $13.0{ }^{\circ} \mathrm{C}$, 无霜期约 218 天。植被类型由北到南依次为温带草原、暖温带 落叶阔叶林、北亚热带含有常绿阔叶树种的落叶阔 叶林。第八次全国森林资源清查资料数据显示，陕 西省森林覆盖率为 $41.4 \%$, 主要分布于秦岭、巴山、 关山、黄龙山和桥山五大林区，占全省森林面积的 $79 \%$, 林分蓄积量占全省森林蓄积量的 $94 \%$, 且以 天然次生林为主(马长欣等, 2010; 曹扬等, 2014)。各 市森林面积由高到低依次为: 汉中 $\left(14582 \mathrm{hm}^{2}\right)$ 、延 安(14 $\left.273 \mathrm{hm}^{2}\right)$ 、安康(12 $\left.551 \mathrm{hm}^{2}\right)$ 、商洛(9 $\left.886 \mathrm{hm}^{2}\right)$ 、 宝鸡(6 $\left.613 \mathrm{hm}^{2}\right)$ 、西安(3 $\left.469 \mathrm{hm}^{2}\right)$ 、渭南(3 $\left.359 \mathrm{hm}^{2}\right)$ 、 咸阳(3 $\left.276 \mathrm{hm}^{2}\right) 、$ 榆林(3 $\left.007 \mathrm{hm}^{2}\right)$ 和铜川(1 $\left.133 \mathrm{hm}^{2}\right)$ 。

\section{2 研究方法}

\subsection{1 研究区及采样点}

本研究根据2009年陕西省森林清查资料中森 林面积和蓄积权重, 把121个样点分布到陕西省各 个地区，并根据各地区森林类型的面积与蓄积构成， 确定了不同森林类型、不同地区的调查样点数, 2011 年在全省对121个样点进行了调查分析(图1)。 


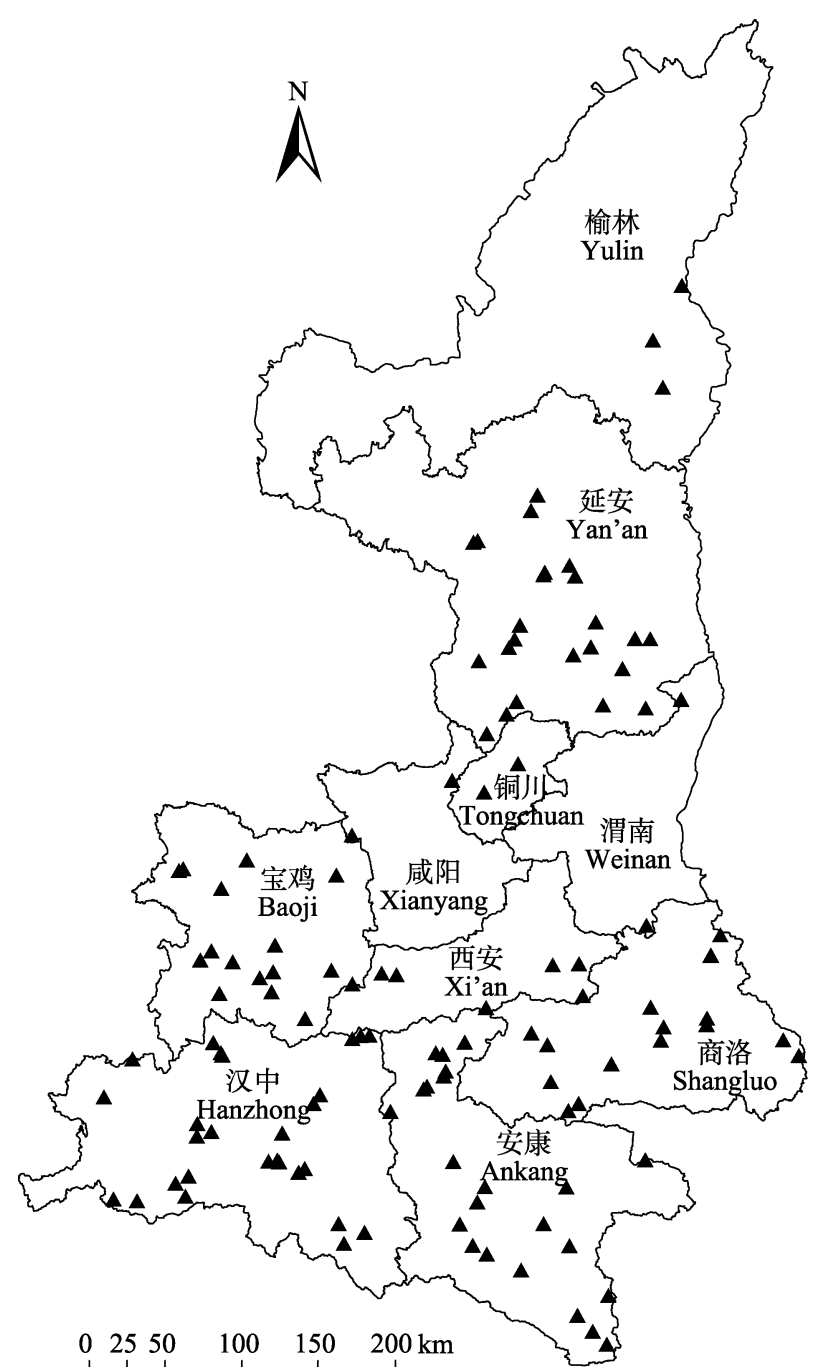

图1陕西省森林样点分布。

Fig. 1 Distribution of sampling sites in the Shaanxi Province.

\subsection{2 样地设置及土壤样品采集}

2011年在全省对 121 个样点开展了森林调查, 各林型主要树种见表1。根据国家林业局编制的《主 要树种龄级与龄组划分》对各林型进行林组划分。 每个样点设置 3 个重复样地, 样地面积为 $20 \mathrm{~m} \times$ $30 \mathrm{~m}$, 记录样地的经度、纬度、海拔、坡向、坡度、 坡位、郁闭度等, 并从陕西省气象局得到样点所在 地的年平均气温、年降水量等信息。

土壤样品采集在去除枯落物层后, 采用土钻法 按对角线在每块样地的上、中、下部各取一个 $1 \mathrm{~m}$ 深的土芯(按0-10、10-20、20-30、30-50和50-100 cm 分层取样), 将同一样地的同层次土样混合均匀, 带 回实验室风干、磨碎, 过篮后保存待测。同时, 在样 地内选择代表性较强的地段挖取一个深度为 $1 \mathrm{~m}$ 的 土壤剖面(剖面厚度不足 $1 \mathrm{~m}$ 深时, 至基岩为止), 采 用环刀法取各层原状土, 带回实验室在 $105{ }^{\circ} \mathrm{C}$ 烘干 用于土壤容重的测定。

\subsection{3 室内测定}

土壤有机碳含量采用重铬酸钾氧化法测定。

\subsection{4 土壤有机碳储量的估算}

根据不同森林类型各土层的土壤有机碳含量、 土层厚度及容重分别计算各层(0-10、10-20、20-30、 30-50和50-100 cm按实际深度计算)土壤有机碳密 度 $\left(\mathrm{t} \cdot \mathrm{hm} \mathrm{m}^{-2}\right)$, 公式如下:

$$
\text { Csoci }=\sum_{j=1}^{5}\left[\frac{1}{10} \text { SOC }_{i, j} \times B D_{i, j} \times \text { Depth }_{i, j}\right]
$$

表1 陕西省主要森林类型及主要树种

Table 1 The forest types and their dominant tree species in Shaanxi Province

\begin{tabular}{|c|c|c|}
\hline 林型(代码) Forest type (Code) & 主要树种 Dominant tree species & 样点数 No. of plots \\
\hline 辽东栎林 Forest of Quercus wutaishanica (A) & 辽东栋 Quercus wutaishanica & 13 \\
\hline 栓皮栋林 Forest of Quercus variabilis (B) & 栓皮栋 Quercus variabilis & 24 \\
\hline 其他栋类林 Other quercus forests (C) & 䲃栋 Quercus aliena, 麻栋 Quercus acutissima & 15 \\
\hline 桦木林 Forest of Betula spp. (D) & 白桦 Betula platyphylla, 红桦 Betula albosinensis & 7 \\
\hline 杨树林 Forest of Populus spp. (E) & $\begin{array}{l}\text { 毛白杨 Populus tomentosa，山杨 Populus davidiana, } \\
\text { 青杨 Populus tcathayana }\end{array}$ & 13 \\
\hline 刺槐林 Forest of Robinia pseudoacacia (F) & 刺槐 Robinia pseudoacacia & 12 \\
\hline 油松林 Forest of Pinus tabuliformis (G) & 油松 Pinus tabuliformis & 12 \\
\hline 其他松类林 Forest of other pines and conifer $(\mathrm{H})$ & $\begin{array}{l}\text { 巴山松 Pinus henryi, 华山松 Pinus armandi, } \\
\text { 马尾松 Pinus massoniana }\end{array}$ & 9 \\
\hline 其他针叶林 Forest of other conifer (I) & 刺柏 Juniperus formosana, 侧柏 Platycladus orientalis & 3 \\
\hline $\begin{array}{l}\text { 软阔与硬阔类林 } \\
\text { Forest of softwood and hardwood }(J)\end{array}$ & $\begin{array}{l}\text { 椿树 Ailanthus altissima, 亱树 Koelreuteria paniculata, } \\
\text { 板栗 Castanea mollissima, 木姜子 Litsea pungens }\end{array}$ & 10 \\
\hline $\begin{array}{l}\text { 针阔混交林 } \\
\text { Mixed coniferous and broad-leaf forest (K) }\end{array}$ & $\begin{array}{l}\text { 油松与辽东栋 Pinus tabulaeformis and Quercus wutaishanica, } \\
\text { 油松与栓皮栋 Pinus tabuliformis and Quercus wutaishanica }\end{array}$ & 3 \\
\hline
\end{tabular}


式中, Csoci 为第 $i$ 类森林土壤有机碳密度 $\left(\mathrm{t} \cdot \mathrm{hm}^{-2}\right)$, $S O C c_{i, j}$ 是第 $i$ 类森林第 $j$ 层 $(j=1,2,3,4,5$, 分别代表 0-10、10-20、20-30、30-50和50-100 cm)土壤有机 碳含量 $\left(\mathrm{g} \cdot \mathrm{kg}^{-1}\right), B D_{i, j}$ 是第 $\mathrm{i}$ 类森林第 $\mathrm{j}$ 层土壤容重 $\left(\mathrm{g} \cdot \mathrm{cm}^{-3}\right), D e p t h_{i, j}$ 是第 $i$ 类森林第 $j$ 层土壤的厚度 $(\mathrm{cm})$ 。

根据森林土壤有机碳密度 $\left(\mathrm{t} \cdot \mathrm{hm}^{-2}\right)$ 计算有机碳 储量(Tg), 公式如下:

$$
\text { Tsoci }=A i \times C s o C i \times 10^{-6}
$$

式中, Tsoci 为第 $i$ 类森林土壤有机碳储量 $(\mathrm{Tg})$, CSOC $i$ 为第 $i$ 类森林土壤有机碳密度 $\left(\mathrm{t} \cdot \mathrm{hm}^{-2}\right), A_{i}$ 为第 $\mathrm{i}$ 类森林的面积 $\left(\mathrm{hm}^{2}\right)$ 。各类森林土壤有机碳储量累加 即为陕西省森林土壤总碳储量。

\subsection{5 数据处理和分析}

使用SPSS 19.0 (SPSS, USA)中的单因素方差分 析方法分析各森林类型土壤有机碳密度间的差异性, 用Person相关性分析方法分析土壤有机碳密度与地 理因子及气候因子的相关性。用SigmaPlot 10.0对各 林型10 cm厚度土壤有机碳密度作图; 利用Arcgis 10.0地理统计分析软件, 基于陕西省地区行政图和 各市森林土壤有机碳密度和碳储量数据, 对陕西省 森林土壤有机碳密度和碳储量进行地理空间分析, 得出陕西省森林土壤有机碳密度和碳储量地理空间 分布图。

\section{2 结果和分析}

\section{1 陕西省森林土壤碳密度和碳储量}

\subsection{1陕西省不同森林类型土壤碳密度和碳储量}

陕西省不同森林类型土壤碳密度差异较大, 介
于(58.26 \pm 5.16$) \mathrm{t} \cdot \mathrm{hm}^{-2}$ 到(141.74 \pm 10.28) $\mathrm{t} \cdot \mathrm{hm}^{-2}$ 之间 (表2), 平均碳密度为90.68 $\mathrm{t} \cdot \mathrm{hm}^{-2}$ 。其中, 华木林土 壤碳密度最大, 软阔与硬阔类林土壤碳密度次之, 刺槐(Robinia pseudoacacia)林和其他柇类林最小。 桦木林和软阔与硬阔类林的土壤碳密度之间差异不 显著, 但显著高于其他各森林类型 $(p<0.05)$ 。软阔 与硬阔类林的土壤碳密度显著高于刺槐林和其他栎 类林 $(p<0.05)$, 但与其他森林类型间无显著性差 异。不同森林类型土壤碳密度可划分为 3 个等级: 桦 木林、软阔与硬阔类林的土壤碳密度较高, 均大于 $100 \mathrm{t} \cdot \mathrm{hm}^{-2}$; 辽东栎(Quercus wutaishanica)、栓皮楿 (Quercus variabilis)、油松(Pinus tabuliformis)、其他 松类、杨属(Populus spp.)和针阔混交林土壤碳密度 次之, 介于 80-100 t.hm ${ }^{-2}$ 之间; 其他栎类林、刺槐林, 以及其他针叶林土壤碳密度较低, 小于 $80 \mathrm{t} \cdot \mathrm{hm}^{-2}$ 。

陕西省不同森林类型土壤碳密度 $(10 \mathrm{~cm}$ 厚度 $)$ 均随土层深度的增加而降低(图2), 表层土壤(0$10 \mathrm{~cm}$ )碳密度最高, 介于14.86-30.63 t $\cdot \mathrm{hm}^{-2}$ 之间, 占0-100 cm 土壤碳密度的 $21.12 \%-33.52 \%$; 各森林 类型中, 针阔混交林表层土壤碳密度最大, 桦木林 次之, 刺槐林最小。

陕西省森林土壤总碳储量为 $579.68 \mathrm{Tg}$ 。不同森 林类型土壤碳储量差异较大, 介于2.34-210.69 Tg 之间。各森林类型中, 软阔与硬阔类林的土壤碳储 量最大, 占全省森林土壤总碳储量的 $36.35 \%$, 其次 是辽东栎林和其他栎类林, 分别占全省土壤总碳储 量的 $19.49 \%$ 和 $10.75 \%$, 而针阔混交林最小, 仅占 $0.56 \%$ 。陕西省森林土壤各层中, 0-30 cm土层碳储 量较高, 占0-100 cm土壤总碳储量的 $50.04 \%$ 。

表2 不同森林类型土壤层碳密度(平均值士标准误差)

Table 2 Carbon density in different soil layers and different forests (mean $\pm S E$ )

\begin{tabular}{lcccccc}
\hline 林型 & \multicolumn{5}{c}{ 土壤碳密度 Carbon density in soil $\left(\mathrm{t} \cdot \mathrm{hm}^{-2}\right)$} \\
\cline { 2 - 7 } Forest type & $\mathrm{I}(0-10 \mathrm{~cm})$ & II $(10-20 \mathrm{~cm})$ & III $(20-30 \mathrm{~cm})$ & IV $(30-50 \mathrm{~cm})$ & $\mathrm{V}(50-100 \mathrm{~cm})$ & 合计 Total \\
\hline $\mathrm{A}$ & $23.91 \pm 1.06^{\mathrm{ab}}$ & $14.13 \pm 0.65^{\mathrm{bc}}$ & $10.11 \pm 0.57^{\mathrm{c}}$ & $14.66 \pm 0.84^{\mathrm{bc}}$ & $24.20 \pm 2.17^{\mathrm{b}}$ & $87.01 \pm 3.81^{\mathrm{bc}}$ \\
$\mathrm{B}$ & $21.29 \pm 1.06^{\mathrm{ab}}$ & $14.02 \pm 0.66^{\mathrm{bc}}$ & $11.11 \pm 0.57^{\mathrm{c}}$ & $17.86 \pm 1.12^{\mathrm{bc}}$ & $33.81 \pm 2.11^{\mathrm{ab}}$ & $98.10 \pm 4.58^{\mathrm{bc}}$ \\
$\mathrm{C}$ & $18.76 \pm 0.86^{\mathrm{ab}}$ & $11.49 \pm 0.68^{\mathrm{bc}}$ & $7.99 \pm 0.52^{\mathrm{c}}$ & $11.61 \pm 0.90^{\mathrm{bc}}$ & $21.09 \pm 1.61^{\mathrm{b}}$ & $70.94 \pm 3.50^{\mathrm{c}}$ \\
$\mathrm{D}$ & $29.93 \pm 2.37^{\mathrm{a}}$ & $21.95 \pm 2.11^{\mathrm{a}}$ & $19.58 \pm 1.63^{\mathrm{a}}$ & $28.47 \pm 3.21^{\mathrm{a}}$ & $41.81 \pm 3.00^{\mathrm{a}}$ & $141.74 \pm 10.28^{\mathrm{a}}$ \\
$\mathrm{E}$ & $20.44 \pm 1.19^{\mathrm{ab}}$ & $13.06 \pm 0.91^{\mathrm{bc}}$ & $9.30 \pm 0.77^{\mathrm{c}}$ & $14.04 \pm 1.19^{\mathrm{bc}}$ & $31.27 \pm 2.96^{\mathrm{ab}}$ & $88.10 \pm 5.31^{\mathrm{bc}}$ \\
F & $14.86 \pm 1.41^{\mathrm{b}}$ & $7.87 \pm 0.88^{\mathrm{c}}$ & $6.34 \pm 0.73^{\mathrm{c}}$ & $9.51 \pm 0.92^{\mathrm{c}}$ & $19.67 \pm 1.74^{\mathrm{b}}$ & $58.26 \pm 5.16^{\mathrm{c}}$ \\
$\mathrm{G}$ & $19.01 \pm 0.97^{\mathrm{ab}}$ & $12.45 \pm 1.00^{\mathrm{bc}}$ & $9.44 \pm 0.61^{\mathrm{c}}$ & $13.06 \pm 0.86^{\mathrm{bc}}$ & $28.34 \pm 2.52^{\mathrm{b}}$ & $82.29 \pm 4.73^{\mathrm{bc}}$ \\
$\mathrm{H}$ & $21.70 \pm 1.44^{\mathrm{ab}}$ & $13.68 \pm 1.19^{\mathrm{bc}}$ & $9.91 \pm 0.97^{\mathrm{c}}$ & $15.24 \pm 2.45^{\mathrm{bc}}$ & $27.16 \pm 3.95^{\mathrm{b}}$ & $87.69 \pm 8.79^{\mathrm{bc}}$ \\
$\mathrm{I}$ & $20.47 \pm 1.57^{\mathrm{ab}}$ & $11.88 \pm 1.49^{\mathrm{bc}}$ & $7.66 \pm 1.05^{\mathrm{c}}$ & $12.70 \pm 2.58^{\mathrm{bc}}$ & $26.02 \pm 5.29^{\mathrm{b}}$ & $78.73 \pm 10.73^{\mathrm{bc}}$ \\
$\mathrm{J}$ & $23.41 \pm 2.44^{\mathrm{ab}}$ & $16.53 \pm 1.87^{\mathrm{ab}}$ & $12.99 \pm 1.50^{\mathrm{b}}$ & $19.54 \pm 2.64^{\mathrm{b}}$ & $34.98 \pm 3.96^{\mathrm{ab}}$ & $107.46 \pm 10.77^{\mathrm{ab}}$ \\
K & $30.63 \pm 4.63^{\mathrm{a}}$ & $13.63 \pm 1.36^{\mathrm{bc}}$ & $9.57 \pm 0.90^{\mathrm{c}}$ & $13.89 \pm 1.65^{\mathrm{bc}}$ & $23.64 \pm 3.08^{\mathrm{b}}$ & $91.36 \pm 9.35^{\mathrm{bc}}$ \\
\hline
\end{tabular}

不同小写字母代表林型间差异性显著 $(p<0.05)$ 。林型见表 1 。

Different lowercase letters indicate significant differences among forest types $(p<0.05)$. Forest types are shown in Table 1 .

www.plant-ecology.com 


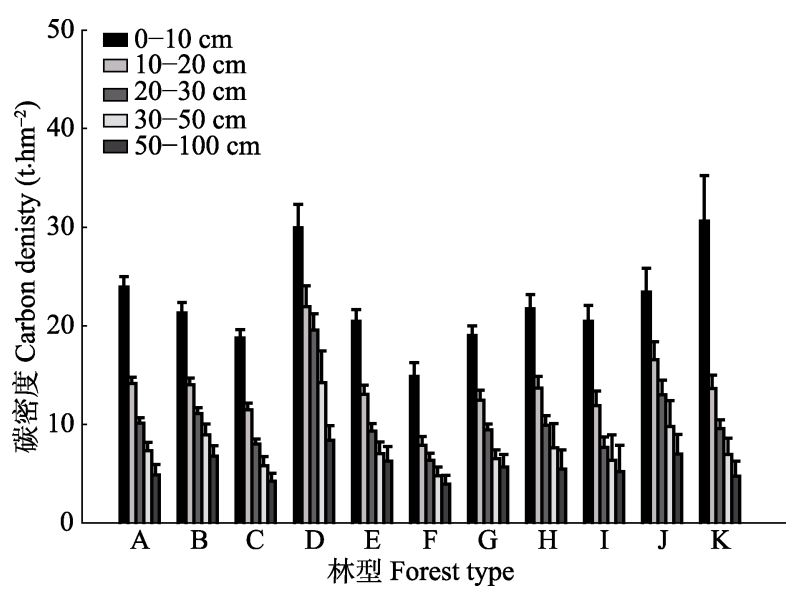

图2 不同森林类型土壤各层 $10 \mathrm{~cm}$ 厚度的碳密度(平均值士 标准误差)。林型见表1。

Fig. 2 Mean soil carbon density of soil $10 \mathrm{~cm}$ thickness in different forest types (mean $\pm S E$ ). Forest types are shown in Table 1.

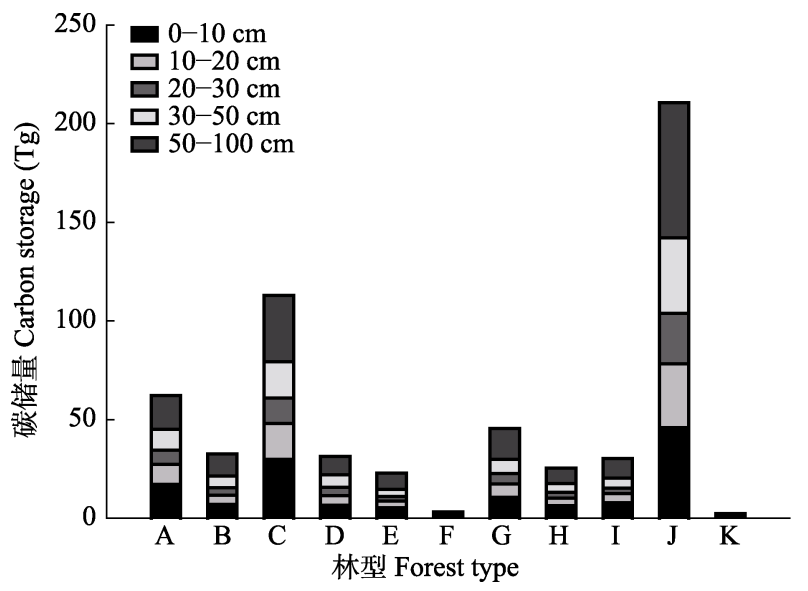

图3陕西省不同森林类型各层土壤碳储量。林型见表1。

Fig. 3 Soil carbon storage in different soil layers in the forests of Shaanxi Province. Forest types are shown in Table 1.

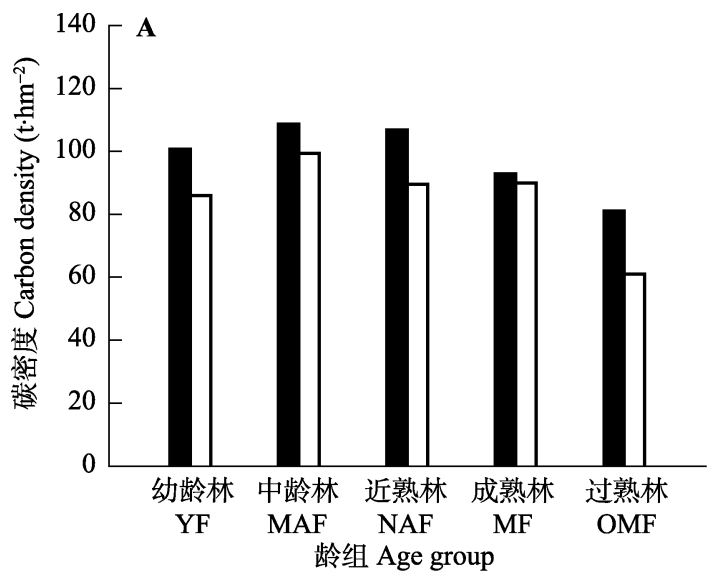

天然林 Natural forest

\subsection{2 天然林和人工林各龄组土壤碳密度和碳储量}

陕西省天然林和人工林的土壤碳密度以中龄 林最高, 过熟林最低, 随着林木的生长, 碳密度先 增加，至中龄林后开始下降。各龄组的土壤碳密度 均表现为天然林高于人工林(图4A), 说明天然林的 碳固存能力较强。

陕西省天然林土壤碳储量 $(467.17 \mathrm{Tg})$ 约为人工 林(112.50 Tg)的4.15倍, 天然林和人工林分别占森 林土壤总碳储量的 $80.59 \%$ 和 $19.41 \%$ 。由图4B可知, 各龄组的土壤碳储量以中龄林最高, 过熟林最低; 其 中, 幼龄林和中龄林是碳储量的主要贡献者, 共占总 碳储量的 $57.30 \%$; 各龄组土壤碳储量均表现为天然 林高于人工林。

\section{2 陕西省森林土壤碳密度与碳储量的地理空间 分布}

由陕西省森林土壤碳密度和碳储量地理空间 分布图(图5)可知, 碳密度较高的地区分布于关中平 原，以宝鸡(113.84 t $\left.\cdot \mathrm{hm}^{-2}\right) 、$ 铜川(113.49 t $\left.\cdot \mathrm{hm}^{-2}\right)$ 和西 安 $\left(112.51 \mathrm{t} \cdot \mathrm{hm}^{-2}\right)$ 三地最高, 而陕西省最北部的榆林 地区土壤碳密度最低(31.38 $\left.\mathrm{t} \cdot \mathrm{hm}^{-2}\right)$, 其他各地碳密 度介于 $70-110 \mathrm{t} \cdot \mathrm{hm}^{-2}$ 之间。

陕西省森林土壤碳储量以安康(114.53 Tg)和汉 中(110.36 Tg)最高, 共占全省森林土壤总碳储量的 $39.60 \%$, 其次为延安 $(98.41 \mathrm{Tg})$, 而铜川 $(7.31 \mathrm{Tg})$ 和 榆林最低(8.13 Tg), 分别占全省森林土壤总碳储量 的 $1.29 \%$ 和 $1.43 \%$ 。

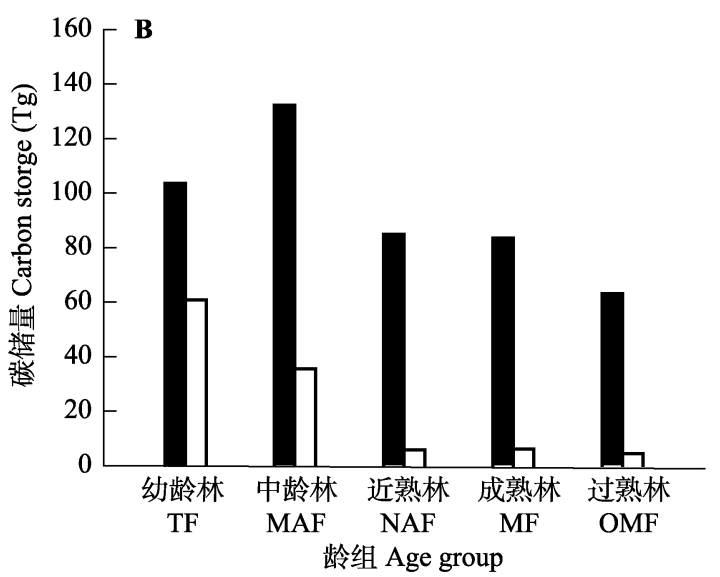

人工林 Artificial forest

图4 陕西省天然林和人工林各龄组土壤碳密度(A)和碳储量 $(\mathrm{B})$ 。

Fig. 4 Soil carbon density (A) and soil carbon storage (B) in natural forests and plantations with different stand ages in Shaanxi Province. MAF, middle-aged forest; MF, mature forest; NAF, near-mature forest; OMF, over-mature forest; YF, young forest. 

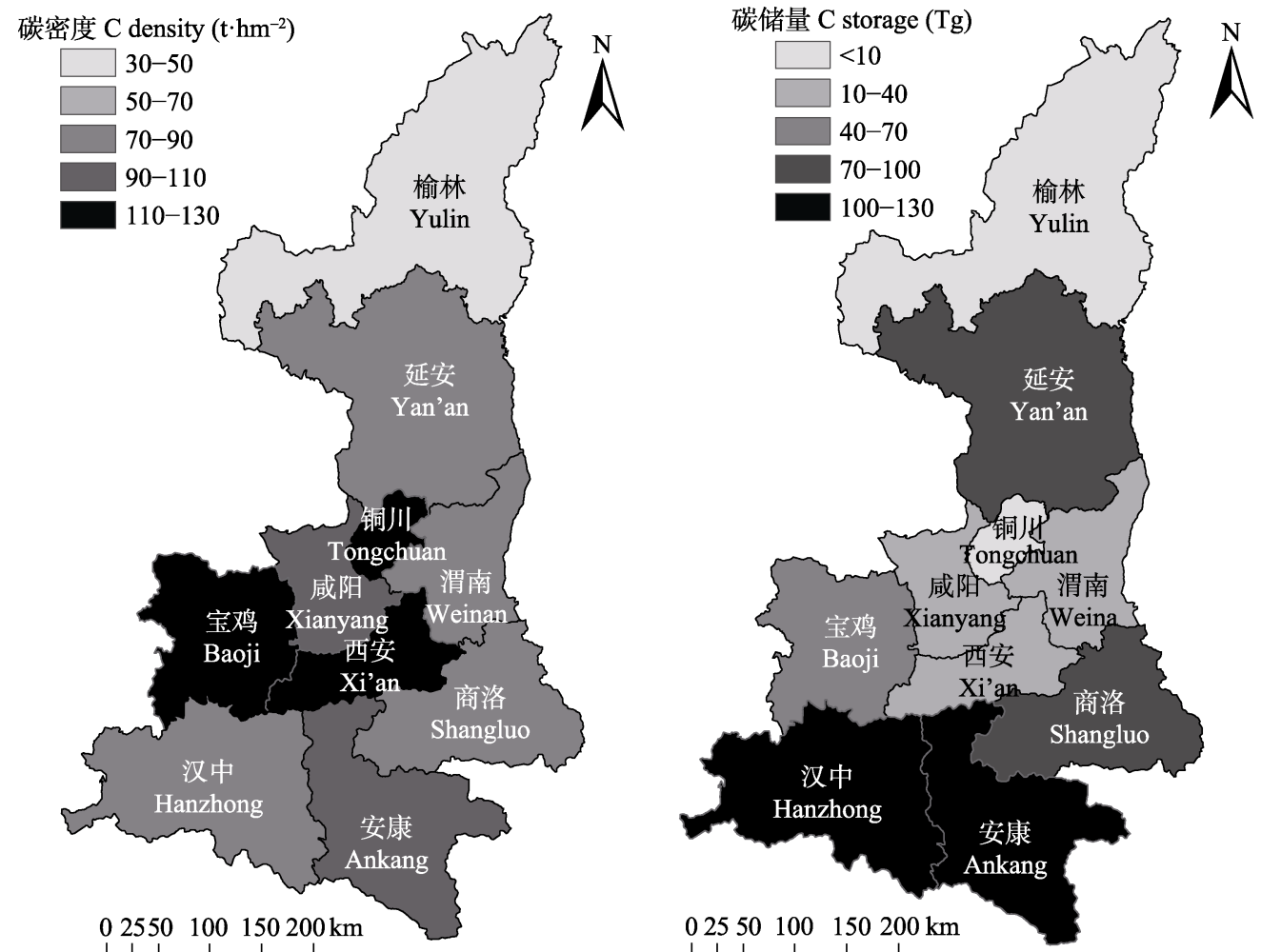

图5 陕西省森林土壤碳密度与碳储量地理分布图。

Fig. 5 Geographical distribution of soil carbon density and carbon storages in Shaanxi forests.
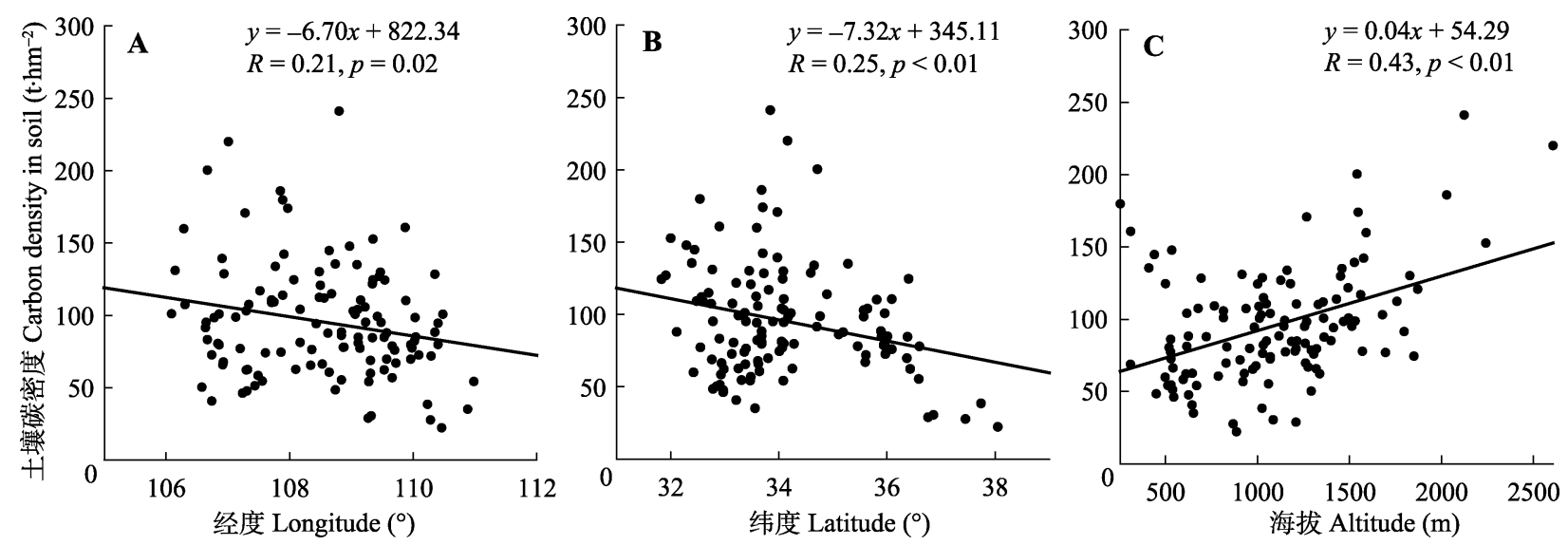

图6 陕西省森林土壤碳密度与经度、纬度及海拔的相关关系。 $R$ 表示回归方程的拟合程度。

Fig. 6 Relationships between forest soil carbon density and longitude, latitude and elevation in Shaanxi Province. $R$ show the fitting degree of regression equation.

\section{3 陕西省森林土壤碳密度随地理因子和气候因} 子的变化

由图6可知，陕西省森林土壤碳密度随经度、纬 度和海拔均呈现出明显的变化, 其中, 土壤碳密度 随经度和纬度的增加逐渐减小, 分别呈显著 $(p<$ $0.05)$ 与极显著 $(p<0.01)$ 的负相关关系; 随海拔高度 的增加逐渐增大，呈极显著的正相关关系 $(p<0.01)$ 。

由图7可知, 陕西省森林土壤碳密度随多年平 均气温的增加逐渐减小, 呈极显著的负相关关系 www.plant-ecology.com $(p<0.01)$; 而随年降水量的增加逐渐增大, 呈显著 的正相关关系 $(p<0.05)$ 。

\section{3 讨论}

\section{1 陕西省森林土壤碳密度和碳储量特征}

森林生态系统在调节全球碳平衡、减缓大气温 室气体等方面具有不可替代的作用(Woodwell et al., 1978), 其土壤碳库是全球陆地碳库的重要组 成部分(徐耀粘和江明喜, 2015), 在全球碳平衡中起 

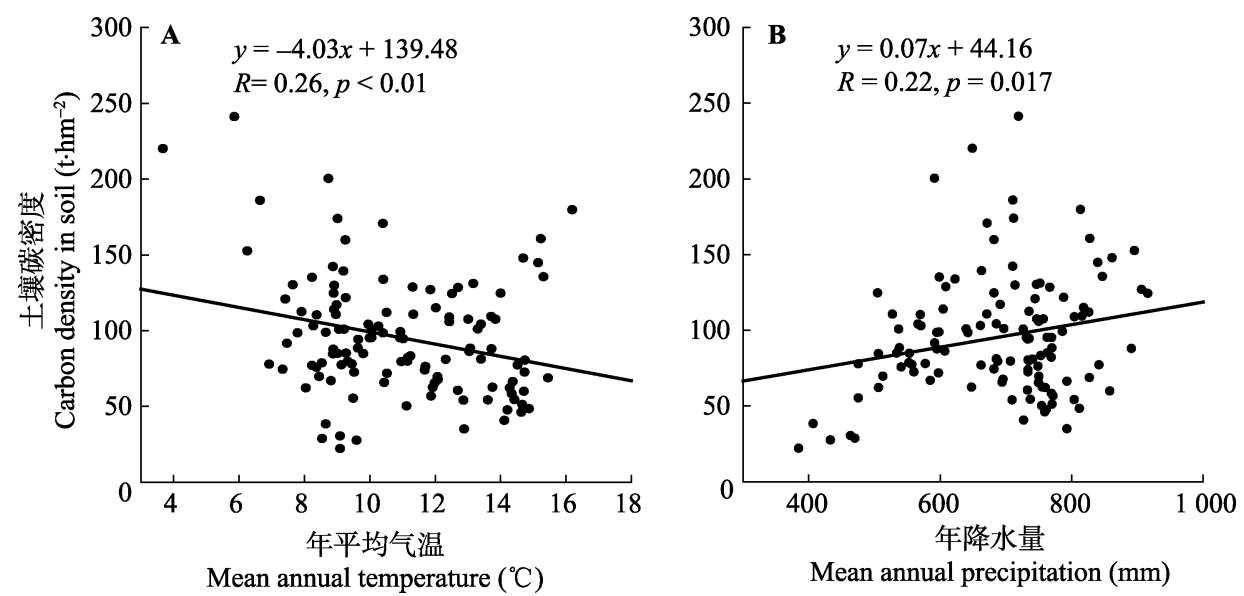

图7 陕西省森林土壤碳密度与气候因子的相关关系。 $R$ 表示回归方程的拟合程度。

Fig. 7 Relationships between forest soil carbon density and climatic factors in Shaanxi Province. $R$ show the fitting degree of regression equation.

着至关重要的作用。本研究中陕西省森林土壤总碳 储量为 $579.68 \mathrm{Tg}$, 约占陕西省森林生态系统碳储量 (790.75 Tg) (崔高阳等, 2015)的71.83\%, 与周玉荣等 (2000)的研究中我国森林土壤碳储量占森林生态系 统总碳储量 $74.6 \%$ 的结果相近。相比于 1994 年 (436.61 Tg)、1999年(451.64 Tg)、2004年(511.30 Tg), 以及 2009 年陕西省森林清查数据所得土壤碳储量 (570.49 Tg), 本研究中, 这几年的森林土壤碳储量 分别增加了 $24.68 \% 、 22.09 \% 、 11.80 \% 、 1.59 \%$ 。这 是因为从1999年起, 陕西省实施了一批重点生态建 设工程, 如天然林资源保护工程和退耕还林工程等, 使陕西省森林面积增加, 植被生长和蓄积有了明显 的好转(李登科等, 2010)。

陕西省各森林类型中, 辽东栎林, 其他栎类林, 软阔与硬阔类林的土壤碳储量较高, 它们对森林土 壤总碳储量的贡献率达到了 $66.59 \%$, 而刺槐林和针 阔混交林的土壤碳储量较低, 对森林土壤总碳储量 的贡献率仅有 $0.97 \%$, 与其森林面积(刺槐林面积为 $566 \mathrm{hm}^{2}$, 针阔混交林面积为 $256 \mathrm{hm}^{2}$ ) 较小有关, 另 外, 刺槐林土壤碳密度较低((58.26 \pm 5.16$\left.) \mathrm{t} \cdot \mathrm{hm}^{-2}\right)$ 对 此也有一定的影响。不同起源的森林中, 天然林土 壤的碳储量高于人工林, 原因可能是天然林在陕西 省森林中所占的比重(81.44\%)较大(曹扬等, 2014)。 另外, 不同龄组的森林土壤碳储量以幼龄林和中龄 林为主, 共占陕西省森林土壤总碳储量的 $57.30 \%$, 这与陕西省人工林中中龄林、幼龄林所占比重 (57.72\%)过大有关(崔高阳等, 2015)。因此, 人工林 的土壤碳储量还具有很大的提升空间。

陕西省森林土壤碳密度为 $90.68 \mathrm{t} \cdot \mathrm{hm}^{-2}$, 略高于
李克让等(2003)对中国森林土壤碳密度的研究结果 $\left(81.39 \mathrm{t} \cdot \mathrm{hm}^{-2}\right)$, 但低于四川(190.45 $\left.\mathrm{t} \cdot \mathrm{hm}^{-2}\right)$ 、湖南 $\left(137.15 \mathrm{t} \cdot \mathrm{hm}^{-2}\right)$ 和江西(102.1 $\left.\mathrm{t} \cdot \mathrm{hm}^{-2}\right)$ 省森林土壤碳密 度(黄从德等, 2008; 宋满珍等, 2010; 李斌等, 2015), 原因可能是陕西省北部地区水热条件相对较差, 不 利于林下凋落物的蓄积与分解, 减少了森林土壤碳 的输入(宋娅丽等, 2015)。

土壤碳的形成与成土母质、植被类型、碳输入、 土壤含水率以及温度有关(Pregitzer \& Euskirchen, 2004)。陕西省不同森林类型土壤层碳密度差异较大, 介于 $(58.26 \pm 5.16) t \cdot h m^{-2}$ 到 $(141.74 \pm 10.28) t \cdot h^{-2}$ 之间, 原因可能是植被类型不同, 导致进入土壤中 的植物残体量以及根系生物量存在较大差异, 进而 改变了土壤碳储量的大小(Zhou et al., 2007; Crow et al., 2009)。此外, 不同森林类型的林下微气候影响 土壤微生物的活性, 进一步影响植被调落物的分解 速率, 从而也可能影响到土壤碳的积累(Wynn et al., 2006; Yang et al., 2007)。桦木林的土壤碳密度显著 高于除软阔与硬阔类林之外的其他各森林类型 $(p<$ $0.05)$, 可能是由于陕西省的桦木林均为天然林, 人 为干扰较弱, 其枯落物碳库更容易累积(Yawei et al., 2013), 进而可能增加了土壤碳库的碳输入量。陕西 省森林土壤0-30 cm 土层中存储的碳占0-100 cm 土 壤总碳储量的 $50.04 \%$, 与Yang等(2007)对中国土壤 碳储量的研究结果 $(0-30 \mathrm{~cm}$ 土层中存储的碳约占 0-100 cm土壤碳的48\%)相近。不同森林类型土壤各 层 $10 \mathrm{~cm}$ 厚度的平均碳密度、碳储量都以表层土壤最 大, 并随土壤深度的增加而降低, 原因可能是地表 枯枝落叶和林木根系分解为土壤提供了丰富的碳 
源。一般认为, 随着林木的生长, 其地上部分的生物 量、胸径、林分密度、植被盖度和郁闭度增加, 对 水热光资源的竞争加剧, 林分内的自然疏枝现象较 为明显, 导致调落物的量增加, 进一步增加了土壤 碳的输入来源, 因此, 森林土壤碳含量会随着林龄 的增加而增加(孙涛, 2011; 苗娟等, 2014)。然而, 本 研究中森林土壤碳密度随着林木的生长呈先增加后 降低的趋势, 可能是由于森林林分密度、植被盖度 和郁闭度的增加改变了林下微气候, 土壤温度和含 水率随之发生变化, 导致限制微生物呼吸的条件发 生变化, 土壤碳被进一步分解(Pregitzer \& Euskirchen, 2004)。对于不同起源的森林, 各龄组均表现为 天然林的土壤碳密度高于人工林, 表明天然林土壤 的碳固存能力高于人工林。

\section{2 陕西省森林土壤碳密度和碳储量的空间分布}

了解碳储量的空间分布对深入认识碳循环机 制和制定应对气候变化的政策至关重要。陕西省森 林土壤碳储量和碳密度的空间分布格局差异较大, 碳储量以位于秦岭、巴山地区的安康、汉中和位于 黄龙山、桥山地区的延安三地较大, 占全省森林土 壤总碳储量的 $56.92 \%$; 汉中、延安两地的碳密度(分 别是 81.80 和 $80.27 \mathrm{t} \cdot \mathrm{hm}^{-2}$ ) 低于全省平均碳密度 $\left(90.68 \mathrm{t} \cdot \mathrm{hm}^{-2}\right)$, 但由于两地森林覆盖面积占到全省 森林总面积的 $40.28 \%$, 其碳储量在全省所占比重较 大。由此可见, 采取封山育林、退耕还林等措施可 以有效地提高森林土壤的碳汇潜力(马琪等, 2012)。 碳密度以宝鸡、铜川、西安三地较大, 其原因可能 是这些区域的自然水热条件较好, 森林的调落物输 入量大, 因此碳的固存能力较高。而地处陕西省最 北部的榆林森林土壤碳密度仅为 $31.38 \mathrm{t} \cdot \mathrm{hm}^{-2}$, 碳储 量仅占全省森林土壤总碳储量的 $1.43 \%$, 这体现了 陕西省各区域碳密度基本上与该地区自然地域降水 分布特征相吻合的特点(李登科等, 2010; 曹扬等, 2014)。另外, 本研究中森林土壤碳储量与碳密度的 分布格局与崔高阳等(2015)对陕西省森林生态系统 整体的研究结果一致, 体现了土壤碳库在森林生态 系统中的重要地位。

\section{3 陕西省森林土壤碳密度随地理和气候因子的 变化}

土壤在空间上呈现出复杂的镶嵌性, 并与各环 境因子发生复杂的相互作用, 因此土壤碳密度的空 间变异性较大(Yang \& Wang, 2005; Zhou, 2007)。本
研究中, 陕西省森林土壤碳密度与经度呈显著的负 相关关系，与黄从德等(2008)对四川森林土壤碳密 度的研究结果一致; 而杜虎等(2014)对广西森林土 壤碳密度的研究结果表明森林土壤碳密度与经度呈 正相关关系。陕西省森林土壤碳密度与纬度呈极显 著的负相关关系, 与魏亚伟等(2013)对东北森林土 壤碳密度的研究结果一致, 但与黄从德等(2008)对 四川森林土壤碳库、周玉荣等(2000)对中国森林土 壤碳库, 以及Jobbágy和Jackson (2000)对全球土壤 碳库的研究结果相反, 这可能是由研究区域与研究 尺度不同而导致的。

海拔是环境因子的综合体现, 对森林土壤碳密 度的影响较大。陕西省森林土壤碳密度随海拔 (254.40-2 $605.00 \mathrm{~m}$ )的增加呈增大的趋势, 与黄从 德等(2008)和杜虎等(2014)的研究结果一致, 主要 是由于不同海拔高度下区域气候有差异, 海拔越高, 土壤温度越低, 微生物活性随之降低, 最终使土壤 碳的分解速率降低, 因而高海拔地区碳存储能力强 (Silver et al., 1999); 另外, 不同海拔高度的小气候 不同导致植被类型的差异, 这也是导致土壤碳密度 随海拔变化的原因(宋娅丽等, 2015)。

本研究分析了陕西省的年平均气温与年降水 量对森林土壤碳密度的影响, 温度对土壤碳的影响 主要体现在两方面: 首先是影响植被的生长, 进而 影响进入土壤中的植物残体量; 其次是影响土壤中 有机质的分解速率(宋娅丽等, 2015)。本研究中, 土 壤碳密度与年平均气温呈极显著的负相关关系, 与 杜虎等(2014)的研究结果一致, 原因可能是温度过 高导致异养呼吸增加, 从而消耗了土壤碳(张城等, 2006)。通常情况下, 土壤碳密度随降水量的增加而 降低, 一方面可能是因为雨量充沛的地区生物循环 旺盛, 有机质代谢快, 土壤固碳能力低(林培松和高 全洲, 2009), 另一方面, 降雨量过大可能会引起水 土流失, 使土壤碳储量损失。然而, 本研究发现, 陕 西省森林土壤碳密度与年降水量呈显著的正相关关 系, 这可能是由于黄土高原降水量少且年内分布不 均, 土壤的干湿交替使团聚体崩溃, 土壤呼吸作用 强度在极短的时间内大幅度提高, 增加了碳的矿化 分解; 同时, 部分土壤微生物在干旱期死亡, 在一 定程度上改变了土壤碳储量(宋娅丽等, 2015)。

\section{4 陕西省森林土壤碳储量估算不确定性分析} 近十几年来, 已有不少学者对中国森林土壤碳 
库进行了研究, 但是由于森林类型的多样性、结构 的复杂性, 以及森林对干扰和变化环境响应的时空 动态变化, 导致我们对森林土壤碳储量的估算存在 较大的不确定性(方精云和王娓, 2007)。不同研究者 采用的研究方法不同, 也会给森林土壤碳储量的估 算带来很大的不确定性, 如本研究采用森林清查资 料与实测数据相结合的方法, 碳储量由不同类型森 林的面积与碳密度乘积累加得到, 因此, 森林面积 和土壤碳密度对碳储量起决定作用。森林面积会随 时间的推移发生变化, 使碳储量的估算产生误差。 而土壤碳密度受森林中调落物的量、土壤温湿度、 土壤类型、林龄以及人为干扰等的影响, 这些都是 造成森林土壤碳储量估算不确定性的因素。另外, 在进行实地调查时, 由于研究区内部分样地的土层 较薄, 土壤剖面可能不足 $1 \mathrm{~m}$, 而在估算碳储量时 是以 $1 \mathrm{~m}$ 为标准的, 从而增加了估算的误差(关晋宏 等, 2016)。

因此, 有必要采用统一的方法, 开展中小尺度 上森林土壤固碳特征的研究, 以减少大尺度研究中 带来的误差, 提高森林土壤碳库研究结果的精准度, 进一步为后续的固碳速率、潜力及机制的分析提供 基础。

\section{4 结论}

本研究利用2009年森林清查数据和2011年样地 实测数据, 分析了陕西省森林土壤碳储量、碳密度 及其分布特征和影响因素。结果显示, 陕西省森林 土壤碳储量为 $579.68 \mathrm{Tg}$, 天然林为主要贡献者; 土 壤碳密度为90.68 $\mathrm{t} \cdot \mathrm{hm}^{-2}$, 高于全国水平。陕西省森 林土壤碳储量与碳密度均存在较大的空间变异性, 土壤碳储量和碳密度以榆林地区最低, 应采取适当 的抚育措施及种植高碳密度树种来提高土壤固碳能 力。陕西省森林土壤碳密度与地理因子和气候因子 间有明显的相关性, 但本研究仅考虑了部分地理或 气候因子, 而决定一个地区土壤碳密度的应该是众 多环境因子, 因此还需进一步分析。由于土壤碳库 具有较强的变异性, 未来应标准化研究方法, 多进 行中小尺度的研究, 以降低研究结果的不确定性。

基金项目 国家自然科学基金(41371506、41201088 和41601058)和国家重点研发计划项目(2016YFC0501703)。
致谢 感谢陕西省林业厅和各市林业部门在野外采 样调查工作中给予的支持和配合。

\section{参考文献}

Cao Y, Chen YM, Jin B, Qu M (2014). Carbon storage and density of forest vegetation and its spatial distribution pattern in Shaanxi Province. Journal of Arid Land Resources and Environment, 28(9), 69-73. (in Chinese) [曹扬, 陈云 明, 晋蓓, 渠美 (2014). 陕西省森林植被碳储量、碳密 度及其空间分布格局. 干旱区资源与环境，28(9), 69-73.]

Crow SE, Lajtha K, Bowden RD, Sulzman EW (2009). Increased coniferous needle inputs accelerate decomposition of soil carbon in an old-growth forest. Forest Ecology and Management, 258, 2224-2232.

Cui GY, Chen YM, Cao Y, An CC (2015). Analysis on carbon stock distribution patterns of forest ecosystems in Shaanxi Province. Chinese Journal of Plant Ecology, 39, 333-342. (in Chinese with English abstract) [崔高阳, 陈云明, 曹 扬, 安淳淳 (2015). 陕西省森林生态系统碳储量分布格 局分析. 植物生态学报, 39, 333-342.]

Cui J, Chen YM, Huang JJ, Wang QF, Yao ZJ, Zhang F (2012). Soil carbon sequestration characteristics of Caragana microphylla plantations and influencing factors in Loess Hilly Semiarid Region. Chinese Journal of Eco-Agriculture, 20, 1197-1203. (in Chinese with English abstract) [崔静, 陈 云明, 黄佳健, 王琼芳, 姚志杰, 张飞 (2012). 黄土丘 陵半干旱区人工柠条林土壤固碳特征及其影响因素. 中国生态农业学报, 20, 1197-1203.]

Du H, Zeng FP, Wang KL, Song TQ, Wen YG, Li CG, Peng WX, Liang HW, Zhu HG, Zeng ZX (2014). Dynamics of biomass and productivity of three major plantation types in southern China. Acta Ecologica Sinica, 34, 2712-2724. (in Chinese with English abstract) [杜虎, 曾馥平, 王克林, 宋同清, 温远光, 李春干, 彭晚霞, 梁宏温, 朱宏光, 曾 昭霞 (2014). 中国南方3种主要人工林生物量和生产力 的动态变化. 生态学报, 34, 2712-2724.]

Fang JY, Wang W (2007). Soil respiration as a key belowground process: Issues and perspectives. Journal of Plant Ecology (Chinese Version), 31, 345-347. (in Chinese with English abstract) [方精云, 王娓 (2007). 作为地下过程 的土壤呼吸: 我们理解了多少? 植物生态学报, 31, 345-347.]

Guan JH, Du S, Chen JM, Wu CR, Li GQ, Deng L, Zhang JG, He QY, Shi WY (2016). Current stocks and rate of sequestration of forest carbon in Gansu Province, China. Chinese Journal of Plant Ecology, 40, 304-317. (in Chinese with English abstract) [关晋宏, 杜盛, 程积民, 吴春 荣, 李国庆, 邓磊, 张建国, 何秋月, 时伟宇 (2016). 甘 肃省森林碳储量现状与固碳速率. 植物生态学报, 40, 304-317.] 
Huang CD, Zhang J, Yang WQ, Zhang GQ (2008). Characteristics of carbon stock in artificial forest ecosystem in Sichuan Province of China. Chinese Journal of Applied Ecology, 19, 1644-1650. (in Chinese with English abstract) [黄从德, 张健, 杨万勤, 张国庆 (2008). 四川人 工林生态系统碳储量特征. 应用生态学报, 19, 16441650.]

Ji YH, Guo K, Ni J, Xu XN, Wang ZG, Wang SD (2016). Current forest carbon stocks and carbon sequestration potential in Anhui Province, China. Chinese Journal of Plant Ecology, 40, 395-404. (in Chinese with English abstract) [汲玉河, 郭柯, 倪健, 徐小牛, 王志高, 王树东 (2016). 安徽省森林碳储量现状及固碳潜力. 植物生态学报, 40 , 395-404.]

Jobbágy EG, Jackson RB (2000). The vertical distribution of soil organic carbon and its relation to climate and vegetation. Ecological Applications, 10, 423-436.

Kang YX, Liu JJ, Kang BW et al. (2010). Evaluation of Forest Ecosystem Services in Shaanxi Province. Northwest Agriculture and Forestry University Press, Yangling, Shaanxi. (in Chinese) [康永祥, 刘建军, 康博文等 (2010). 陕西 省森林生态系统服务功能及其评估. 西北农林科技大 学出版社, 陕西杨凌.]

Lal R (2004). Soil carbon sequestration impacts on global climate change and food security. Science, 304, 1623-1627.

Li B, Fang X, Li Y, Xiang WH, Tian DL, Chen XY, Yan WD, Deng DH (2015). Dynamic properties of soil organic carbon in Hunan's forests. Acta Ecologica Sinica, 35, 42654278. (in Chinese with English abstract) [李斌, 方晰, 李 岩, 项文化, 田大伦, 谌小勇, 间文德, 邓东华 (2015). 湖南省森林土壤有机碳密度及碳库储量动态. 生态学 报, 35, 4265-4278.]

Li DK, Fan JZ, Wang J (2010). Change characteristics and their causes of fractional vegetation coverage (FVC) in Shaanxi Province. Chinese Journal of Applied Ecology, 21, 2896-2903. (in Chinese with English abstract) [李登科, 范建忠, 王娟 (2010). 陕西省植被覆盖度变化特征及其 成因. 应用生态学报, 21, 2896-2903.]

Li J (2008). Study on Soil Carbon Stock and Its Spatial Distribution, Influence Factors in the Forest of China. Master degree dissertation, Sichuan Agricultural University, Ya’an, Sichuan. 18-21. (in Chinese with English abstract) [李江 (2008). 中国主要森林群落林下土壤有机碳储量 格局及其影响因子研究. 硕士学位论文, 四川农业大 学, 四川雅安. 18-21.]

Li KR, Wang SQ, Cao MK (2003). Carbon storage of vegetations and soil in China. Science in China Series D: Earth Sciences, 33, 72-80. (in Chinese) [李克让, 王绍强, 曹明 奎 (2003). 中国植被和土壤碳咜量. 中国科学 $\mathrm{D}$ 辑: 地 球科学, 33, 72-80.]

Lin PS, Gao QZ (2009). Study on the soil organic carbon storage and vertical distribution of several forest types in mountain area of Northeast Guangdong. Journal of Soil and Water Conservation, 23, 243-247. (in Chinese with English abstract) [林培松, 高全洲 (2009). 粤东北山区 几种森林土壤有机碳储量及其垂直分配特征. 水土保 持学报, 23, 243-247.]

Liu BY (2015). Characteristics of Carbon Storage of Forest Ecosystem in Shaanxi. Master degree dissertation, Northwest Agriculture and Forestry University, Yangling, Shaanxi. 1-69. (in Chinese with English abstract) [刘冰燕 (2015). 陕西省森林生态系统碳储量特征研究. 硕士学 位论文, 西北农林科技大学, 陕西杨凌. 1-69.]

Ma CX, Liu JJ, Kang BW, Sun SH, Ren JH (2010). Evaluation of forest ecosystem carbon fixation and oxygen release services in Shaanxi Province from 1999 to 2003. Acta Ecologica Sinica, 30, 1412-1422. (in Chinese with English abstract) [马长欣, 刘建军, 康博文, 孙尚华, 任 军辉 (2010). 1999-2003年陕西省森林生态系统固碳释 氧服务功能价值评估. 生态学报, 30, 1412-1422.]

Ma Q, Liu K, Zhang H (2012). Carbon storage by forest vegetation and its spatial distribution in Shaanxi. Resource Science, 34, 1781-1789. (in Chinese with English abstract) [马琪, 刘康, 张慧 (2012). 陕西省森林植被碳储量及 其空间分布. 资源科学, 34, 1781-1789.]

Miao J, Zhou CY, LI SJ, Yan JH (2014). Accumulation of soil organic carbon and total nitrogen in Pinus yunnanensis forests at different age stages. Chinese Journal of Applied Ecology, 25, 625-631. (in Chinese with English abstract) [苗娟, 周传艳, 李世杰, 间俊华 (2014). 不同林龄云南 松林土壤有机碳和全氮积累特征. 应用生态学报, 25, 625-631.]

Post WM, Emanuel WR, Zinke PJ, Stangenberger AG (1982). Soil carbon pools and world life zones. Nature, 298, 156159.

Pregitzer KS, Euskirchen ES (2004). Carbon cycling and storage in world forests: Biome patterns related to forest age. Global Change Biology, 10, 2052-2077.

Silver WL, Lugo AE, Keller M (1999). Soi1 oxygen availability and biogeochemistry along rainfall and topographic gradients in upland wet tropical forest soil. Biogeochemistry, 44, 301-328.

Smith P, Fang C, Dawson JJC, Moncrieff JB (2008). Impact of global warming on soil organic carbon. Advances in Agronomy, 97, 1-43.

Song C, Chen YM, Cao Y, Tang YK, Lu Y (2015). Characteristics of soil carbon sequestration in Pinus tabulaeformis plantations and influencing factors in the Loess Hilly Region. Science of Soil and Water Conservation, 13(3), 7682. (in Chinese with English abstract) [宋超, 陈云明, 曹 扬, 唐亚坤, 陆媛 (2015). 黄土丘陵区油松人工林土壤 固碳特征及其影响因素. 中国水土保持科学, 13(3), 76-82.]

Song MZ, Liu QJ, Wu ZR, Ouyang XZ (2010). Organic carbon

www.plant-ecology.com 
storage of forest soil in Jiangxi Province. Journal of Nanjing Forest University: Natural Science Edition, 34(2), 6-10. (in Chinese with English abstract) [宋满珍, 刘琪璟, 吴自荣, 欧阳勋志 (2010). 江西省森林土壤有机碳储量 研究. 南京林业大学学报: 自然科学版, 34(2), 6-10.]

Song YL, Kang FF, Han HR, Cheng XQ (2015). Analysis on effect of nature factors on forest soil carbon storage in China. World Forestry Research, 28(3), 6-12. (in Chinese with English abstract) [宋娅丽, 康峰峰, 韩海荣, 程小琴 (2015). 自然因子对中国森林土壤碳储量的影响分析. 世界林业研究, 28(3), 6-12. ]

Sun T (2011). Soil Carbon Flux and Storage Were Measured Across a Chronosequence of Secondary Forests Dominated by Betula platyphylla in Xiaoxing'an Mountain, China. Master degree dissertation, Northeast Forestry University, Harbin. 23-29. [孙涛 (2011). 小兴安岭不同 年龄序列白桦天然次生林的土壤碳通量和碳咜量. 硕 士学位论文, 东北林业大学, 哈尔滨. 23-29.]

Wang QF, Chen YM, Liu XM, Cui J, Ai ZM (2013). Dynamics of soil organic carbon and its influencing factors in Artemisia gmelinii community in Loess Hilly Region. Pratcultural Science, 30(1), 1-8. (in Chinese with English abstract) [王琼芳, 陈云明, 刘小梅, 崔静, 艾泽民 (2013). 黄土丘陵区铁杆蒿群落表层土壤有机碳动态及其影响 因子. 草业科学, 30(1), 1-8.]

Wang XC, Qi G, Yu DP, Zhou L, Dai LM (2011). Carbon storage, density, and distribution in forest ecosystems in Jilin Province of Northeast China. Chinese Journal of Applied Ecology, 22, 2013-2020. (in Chinese with English abstract) [王新闯, 齐光, 于大炮, 周莉, 代力民 (2011). 吉林省森林生态系统的碳储量、碳密度及其分布. 应用 生态学报, 22, 2013-2020.]

Wei YW, Yu DP, Wang QJ, Zhou L, Zhou WM, Fang XM, Gu XP, Dai LM (2013). Soil organic carbon density and its influencing factors of major forest types in the forest region of Northeast China. Chinese Journal of Applied Ecology, 24, 3333-3340. (in Chinese with English abstract) [魏亚伟, 于大炮, 王清君, 周莉, 周旺明, 方向 民, 谷晓萍, 代力民 (2013). 东北林区主要森林类型土 壤有机碳密度及其影响因素. 应用生态学报, 24, 33333340.]

Woodwell GM, Whittacker RH, Reiners WA, Likens GE, Del-
Delwiche CC, Botkin DB (1978). The biota and the world carbon budget. Science, 199, 141-146.

Wynn JG, Bird MI, Vellen L, Grand-Clement E, Carter J, Berry SL (2006). Continental-scale measurement of the soil organic carbon pool with climatic, edaphic, and biotic controls. Global Biogeochemical Cycles, 20, GB1007. doi: 10.1029/2005 GB002576.

Xu YZ, Jiang MX (2015). Forest carbon pool characteristics and advances in the researches of carbon storage and related factors. Acta Ecologica Sinica, 35, 926-933. (in Chinese with English abstract) [徐耀粘, 江明喜 (2015). 森林碳库特征及驱动因子分析研究进展. 生态学报, 35, 926-933.]

Yang Y, Mohammat A, Feng J, Zhou R, Fang J (2007). Storage, patterns and environmental controls of soil organic carbon in China. Biogeochemistry, 84, 131-141.

Yawei W, Maihe L, Hua C, Bernard J. Lewis, Dapao Y, Li Z, Wangming Z, Xiangmin F, Wei Z, Limin D (2013). Variation in carbon storage and its distribution by stand age and forest type in boreal and temperate forests in Northeastern China. PLOS ONE, 8, e72201. doi: 10.1371/journal.Pone. 0072201.

Zhang C, Wang SQ, Yu GR, He HL, Zhang WJ, Wang BL, Chen QM, Wu ZF (2006). Analysis of soil organic carbon storage in typical forest types in eastern China. Resources Science, 28(2), 97-103. (in Chinese with English abstract) [张城, 王绍强, 于贵瑞, 何洪林, 张文娟, 王伯伦, 陈 庆美, 吴志峰 (2006). 中国东部地区典型森林类型土壤 有机碳储量分析. 资源科学, 28(2), 97-103.]

Zhou GY, Guan L, Wei XH, Zhang DQ, Zhang QM, Yan JH, Wen DZ, Liu JX, Liu SG, Huang ZL, Kong GH, Mo JM, Yu QF (2007). Litterfall production along successional and altitudinal gradients of subtropical monsoon evergreen broadleaved forests in Guangdong, China. Plant Ecology, 188, 77-89.

Zhou YR, Yu ZL, Zhao SD (2000). Carbon storage and budget of major Chinese forest types. Acta Phytoecologica Sinica, 24, 518-522. (in Chinese with English abstract) [周玉荣, 于振良, 赵士洞 (2000). 我国主要森林生态系统碳咜量 和碳平衡. 植物生态学报, 24, 518-522.]

特邀编委: 李胜功 责任编辑: 王 葴
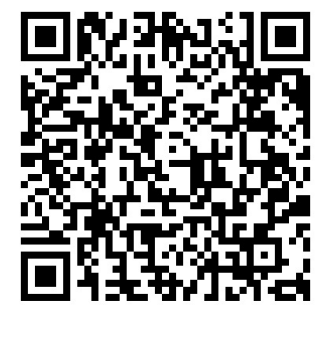

doi: 10.17521/cjpe.2017.0102 